\title{
COMPARATIVE HISTOPATHOLOGICAL CHANGES OF LIVER, KIDNEY AND APPENDIX OF RABBITS TREATED WITH INORGANIC NANO CHROMIUM TO AMELIORATE HEAT STRESS EFFECT
}

\author{
Sahar H. El-Nagar ${ }^{1 *}$, Mohamed A. Helal ${ }^{1}$, Shawky Mahmoud² ${ }^{2}$ Leanne Dillard ${ }^{3}$
}

'Department of Animal Wealth Development, Faculty of Veterinary Medicine, Kafrelsheikh University, 33516, Egypt, ${ }^{2}$ Department of Physiology, Faculty of Veterinary Medicine, Kafrelsheikh University, ${ }^{3}$ Department of Animal Sciences, Auburn University, Auburn, 36849 USA

${ }^{*}$ Corresponding author, E-mail: sahr_hamdy@vet.kfs.edu.eg

\begin{abstract}
The objective of the current experiment was to describe the effects of nanochromium chloride $\left(\mathrm{CrCl}_{3}\right)$ on chronic hyperthermia $\left(32.8 \pm 1.5^{\circ} \mathrm{C}\right)$ on rabbit liver, kidney, and appendix in comparison with rabbits at room temperature $\left(24.5 \pm 1.3^{\circ} \mathrm{C}\right)$ and treated with the same concentration of nano-chromium chloride. For this study, 108 rabbits of two different breeds (New Zealand White and Rex) were used and randomly allocated into 12 groups. The study was conducted as a completely randomized $2 \times 2 \times$ 3 factorial $(n=9)$ design. Treatments were temperature, breed, and concentration of nano-chromium chloride $(0,1$, or $2 \mathrm{mg} / \mathrm{L})$ the results showed that heat stress caused granular hepatic vacuolation, severe congestion of the central vein, and sinusoids in the liver. As well as degenerative changes within the epithelial lining of tubules in the kidney and lymphoid depletion in the appendix. The liver tissue of the New Zealand rabbits was affected more by heat stress than Rex Rabbits, but no difference was observed in the kidney or appendix tissues. The addition of $2 \mathrm{mg} / \mathrm{L}$ nano-chromium was more effective than $1 \mathrm{mg} / \mathrm{L}$ on the heat stressed rabbit tissues, but it caused hepatic vacuolation with glycogen infiltration in liver tissue and mild vacuolation in the renal tubular epithelium.
\end{abstract}

Key words: rabbit; nano-chromium; heat stress; histopathology

\section{Introduction}

The thermal comfort zone for rabbits is $21^{\circ} \mathrm{C}$. Any elevation from this temperature is considered heat stress (1). Heat stress is divided into two types acute and chronic heat stress. This division depends on the period of exposure and the presence of tissue damage including: pyknosis, apoptosis, necrotic areas, and an increase in melanomacrophage centers in liver tissues through, DNA digestion and cell mem- brane destruction $(2,3)$. Previous studies (4-6) observed vacuolated hepatic degeneration with dilation and congestion of sinusoid, widespread necrosis, and infiltration of leukocyte in some parts of the liver and kidney in heat stressed rabbits. The authors also reported damage to the glomeruli of the kidneys. As a consequence, Ondruska et al. (7) reported high animal mortality rates, leading to economic losses for rabbit producers during summer season. 
More recent studies have tried to reduce heat stress through different management and nutritional methods. Nano-chromium is one of the most important nutritional supplements that can be used to decrease and possibly eliminate heat stress damage. However, low doses must be used as higher doses may lead to adverse animal effects such as degenerative changes and necrosis in liver as well as hyaline casts in kidney and tubules and glomeruli (8).

Chromium is an essential trace mineral required for most vital metabolic processes. It is used in carbohydrate, protein, and lipid metabolism (9); therefore it has anabolic effects during periods of stress, including heat stress. Research has shown that nano-chromium has an anabolic effect when used in low concentrations and enhances the nucleic acid synthesis in the liver of the mouse (10). The objective of the current study was to determine what dosage of nano-chromium chloride is needed to ameliorate the degenerative changes in the vital tissues of heat stressed rabbits.

\section{Materials and methods}

This study was carried out at the Department of Animal Wealth Development in the Faculty of Veterinary Medicine at Kafrelsheikh University in Kafrelsheikh, Egypt. The experiment was approved by the guiding of committee on Animal Welfare and Ethics of the Faculty of Veterinary Science, Kafrelsheikh University, in accordance with Egyptian national laws regarding animal welfare. One hundred eight weaning aged rabbits of two different breeds (Rex and New Zealand White; $35 \pm 3$ and $33 \pm 2 \mathrm{~d}$ weaning age, respectively) were used to evaluate the effect of nano-chromium chlordie on liver, kidney, and appendix tissues.

\section{Experimental design}

Each breed had an initial body weight of $602 \pm 9.5$ and $531 \pm 6.5 \mathrm{~g}$ for Rex and New Zealand Breed, respectively. Animals of each bred were divided equally into 6 groups with 9 rabbits in each group. Three groups of each breed were subjected to severe heat stress $\left(32.8 \pm 1.5^{\circ} \mathrm{C}\right.$; HT) and the other three groups were reared under room temperature conditions $\left(24.5 \pm 1.3{ }^{\circ} \mathrm{C}\right.$; RT) (11). Each group contained 3 replicates with 3 rabbits in each replicate. Each replicated group was reared on wire cages $50 \times 50 \times 50 \mathrm{~cm}$ and fed commercial rabbit pellets ( $18 \%$ crude protein) ad libitum.

The nano-chromium particles were prepared by chemical precipitation method of chromium chloride salt (12), and then characterized by transmission electron microscope (TEM) at the Nanotechnology Institution of Kafrelsheikh University, Egypt. The resulting particles were $40-60 \mathrm{~nm}$. These particles were then added to the drinking water at 3 different concentrations $(0,1$ or $2 \mathrm{mg} / \mathrm{L} ; \mathrm{C}, 1$, and 2, respectively) for the duration of the 8 week study. At the end of the experiment rabbits were slaughtered for tissue collection. The liver, kidney and appendix tissues were collected in $10 \%$ formalin, sectioned, and stained with $\mathrm{H} \& \mathrm{E}$ stain for microscopic examination (13).

\section{Results}

\section{Liver}

The liver of the control groups from both breeds and untreated with nano-chromium showed the normal arrangement of the hepatocytes in cords around the central vein and normal sinusoids (Figure 1- A and C). However, the liver of the groups that were exposed to heat stress but untreated with nano-chromium showed that the New Zealand breed was more susceptible to heat stress than the Rex breed. This is due to the appearance of severe congestion of the central vein and sinusoids, as well as granular hepatic vacuolation (Figure 1-B and D). Mild hepatic valuation in New Zealand rabbits treated with $1 \mathrm{mg} / \mathrm{L}$ nanochromium at room temperature was observed (Figure 2). This is consistent with excessive glycogen storage in the liver. This was also seen when New Zealand rabbits received the same concentration of nano-chromium, but that were also exposed to heat stress (Figure 2C). However, when Rex Rabbits were treated with $1 \mathrm{mg} / \mathrm{L}$ of nano-chromium under room temperature conditions, they appeared to have 
normal hepatocyte and liver tissue as seen in Figure 2-B. When exposed to heat stress with the same concentration of nano-chromium, the Rex rabbits responded the same as the New Zealand rabbits, and also appeared to have congestion of the sinusoids. The addition of 2 $\mathrm{mg} / \mathrm{L}$ nano-chromium caused hepatic vacuolation with glycogen infiltration that was severe in New Zealand breeds (Figure 3-A) and mild in Rex Rabbits (Figure 3-B). While in animals exposed to heat stress, the same effect was observed in both breeds which appears as marked decrease in hepatic vacuolation.

\section{Kidney}

There was no observable difference in kidney tissues between breeds under the same temperature conditions. Under room temperature conditions, the two breeds showed normal renal glomeruli and tubules (Figure 4-A and C). However under heat stress, they showed degenerative changes within the lining epithelium of the renal tubules (Figure 4-B and D). In regards to renal tissues, there was no observable difference in the response between the breeds when treated with $1 \mathrm{mg} / \mathrm{L}$ nanochromium and under the same temperature (Figure 5-A and C). The tissue appeared to be normal under room temperature conditions. Mild degenerative changes in the lining of the epithelium of the renal tubules appeared in heat stressed animals (Figure 5-B and D). In rabbits treated with $2 \mathrm{mg} / \mathrm{L}$ nano-chromium, there was no observable difference in response between two breeds under room temperature. Rex rabbits showed normal renal glomeruli and tubules (Figure 6-A). The New Zealand rabbits showed normal renal glomeruli, but showed mild vacuolation of the renal tubular epithelium (Figure 6-B). There was also no difference between the two breeds under heat stress compared with New Zealand under room temperature.

\section{Appendix}

Under room temperature conditions and treated with $0 \mathrm{mg} / \mathrm{L}$ nano-chromium, the two breeds showed normal lymphoid follicles (Figure 7-A and C), but heat stress caused a mild lymphoid depletion in the germinal center of the follicle of Rex rabbits and on the basal follicle of the New Zealand rabbits (Figure 7$\mathrm{B}$ and $\mathrm{D})$. When rabbits were treated with $1 \mathrm{mg} / \mathrm{L}$ nano-chromium under room temperature conditions, they were not different from the untreated rabbits under the same temperature (Figure 8-A and $\mathrm{C}$ ). However under heat stress, the addition of $1 \mathrm{mg} / \mathrm{L}$ of nanochromium ameliorated the lymphoid depletion that resulted from the heat stress in untreated rabbits (Figure 8-B and C). Figure 9 from A to $\mathrm{D}$ showed that there was no difference between breeds treated with $2 \mathrm{mg} / \mathrm{L}$ nanochromium under different temperature treatment.

\section{Discussion}

\section{Liver}

The granular hepatic vacuolations resulting from exposure to heat stress observed in Figure 1 may be due to the activation of mitochondrial reactive oxygen species (ROS; 14) which can lead to cytotoxicity, apoptotic cell death, and necrosis (15). This degenerative condition appears as vacuoles in hepatocytes. However, the severe congestion of the central vein was likely due to the fact that the liver has the densest concentration of mitochondria, which are overloaded during stress. This can lead to increased blood supply to this organ as compensatory mechanism (16). Figure 2-A and $\mathrm{B}$ represent the liver tissue unexposed to heat stress and treated with $1 \mathrm{mg} / \mathrm{L}$ nanochromium. The New Zealand breed showed a better response to nano-chromium treatments than the Rex breed. This is evident in the mild hepatic vacuolation that is consistent with excessive glycogen storage. This is in agreement with Huskisson et al. (17) that illustrated that Cr III enhanced glucose uptake by the liver cells. On the other hand, Muthulingam et al. (18) observed that Cr lead to decreased glycogen in the gills, liver, and kidneys of fish. This was observed in Figure 3, where the degenerative changes and congestion of the liver caused by heat stress disappeared and were replaced by marked hepatic vacuolation due to the increased dose of nano-chromium. 


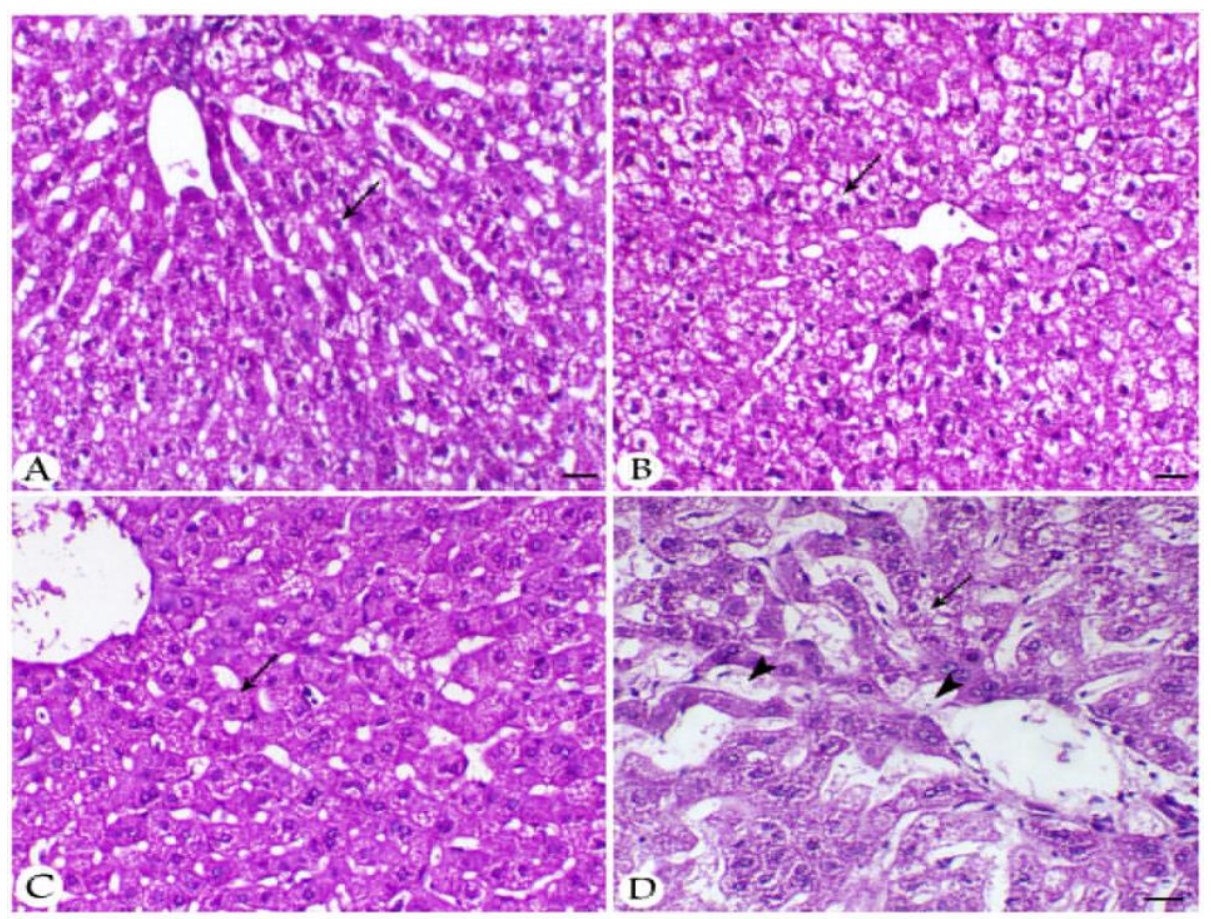

Figure 1: A) Liver of room temperature (R) Rex rabbits showing normal hepatocyte arranged in cords around the central vein (arrow), H\&E, bar $=40 \mu \mathrm{m}$. B) Liver of heat stressed (HS) Rex breed showing granular hepatic vacuolation (arrow), $\mathrm{H} \& \mathrm{E}$, bar $=40 \mu \mathrm{m}$. C) Liver of New Zealand-R rabbits showing normal hepatocytes arranged in cords around the central vein (arrow), H\&E, bar $=40 \mu \mathrm{m}$. D) Liver of HS-New Zealand rabbits showing severe congestion of the central vein and sinusoids (arrowheads) and granular hepatic vacuolation (arrow), $\mathrm{H} \& \mathrm{E}$, bar $=40 \mu \mathrm{m}$

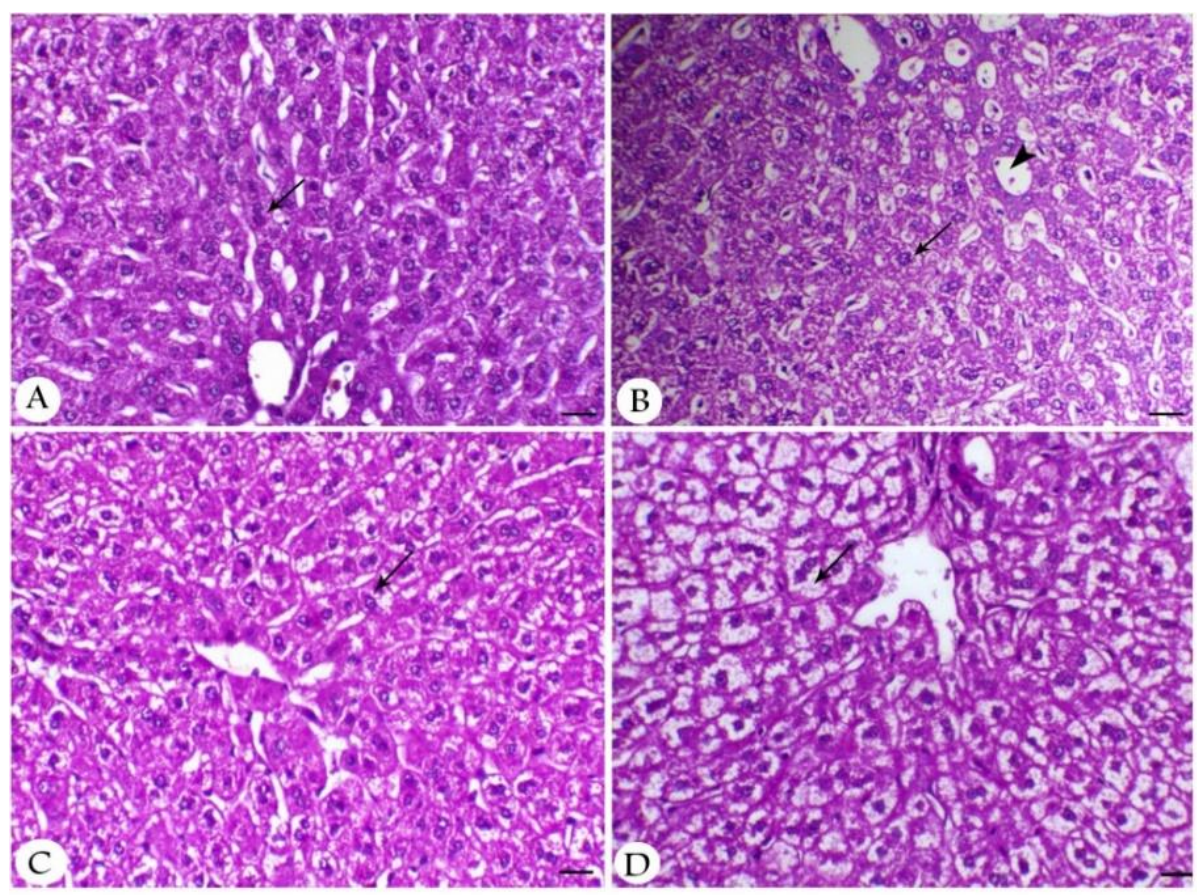

Figure 2:A) Liver of room temperature (R) Rex treated with $1 \mathrm{mg} / \mathrm{L}$ nano-chromium (T1) showing normal hepatocytes (arrow), H\&E, bar $=40 \mu \mathrm{m}$. B) Liver of HS Rex rabbits T1 showing sinusoidal congestion (arrowhead) and mild hepatic vacuolation consistent with hydropic changes (arrow), H\&E, bar $=40$ $\mu \mathrm{m}$. C) Liver of R -New Zealand rabbits T1 showing mild hepatic vacuolation consistent with over glycogen storage (arrow), H\&E, bar $=40 \mu \mathrm{m}$. D) Liver of heat stressed (HS) New Zealand rabbits T1 showing hepatic vacuolation consistent with over glycogen infiltration (arrow), $\mathrm{H} \& \mathrm{E}$, bar $=40 \mu \mathrm{m}$ 


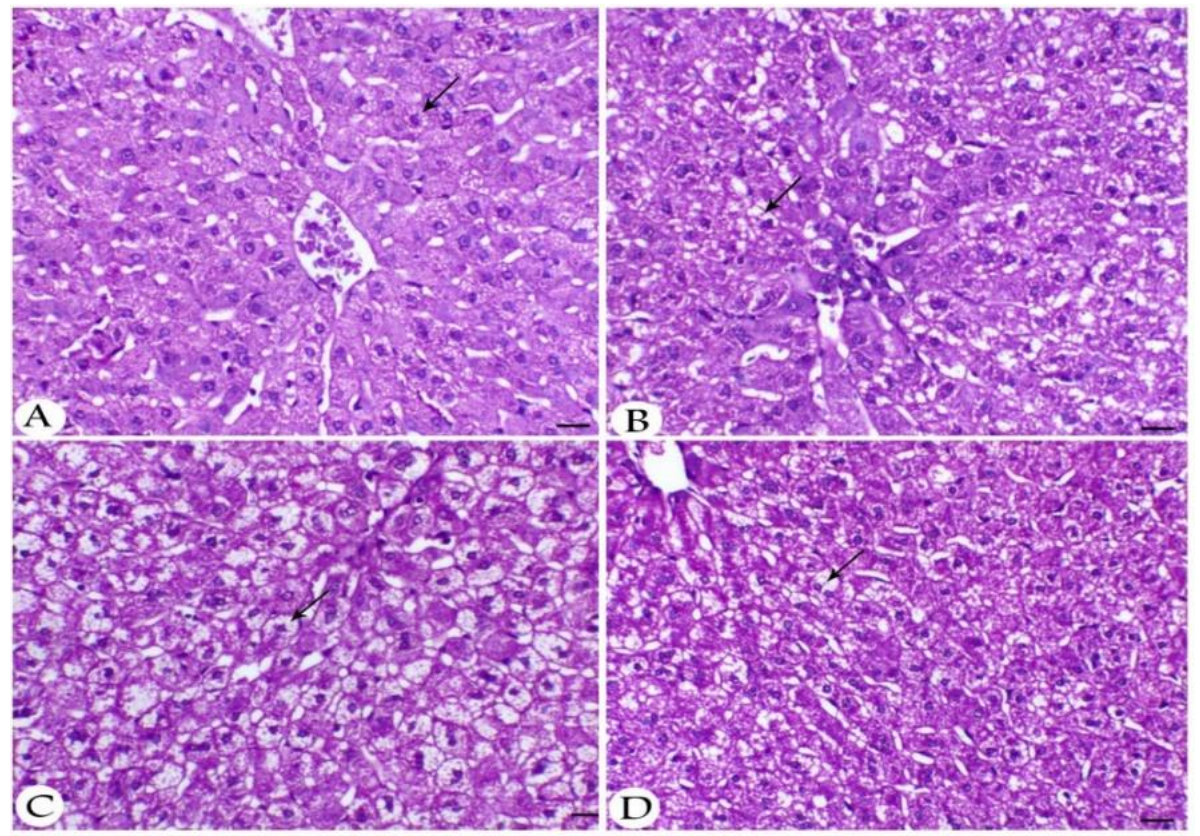

Figure 3:A) Liver of room temperature (R) Rex rabbits treated with $2 \mathrm{mg} / \mathrm{L}$ nano-chromium (T2) showing mild hepatic vacuolation consistent with glycogen storage (arrow), H\&E, bar $=200 \mu \mathrm{m}$. B) Liver of Rex heat stressed (HS) rabbits T2 showing marked decrease of hepatic vacuolation (arrow), H\&E, bar $=40$ $\mu \mathrm{m}$. C) Liver of R New Zealand rabbits T2 showing marked hepatic vacuolation consistent with glycogen infiltration (arrow), H\&E, bar $=200 \mu \mathrm{m}$. D) Liver of HS New Zealand rabbits T2 showing marked decrease of hepatic vacuolation (arrow), $\mathrm{H} \& \mathrm{E}$, bar $=40 \mu \mathrm{m}$

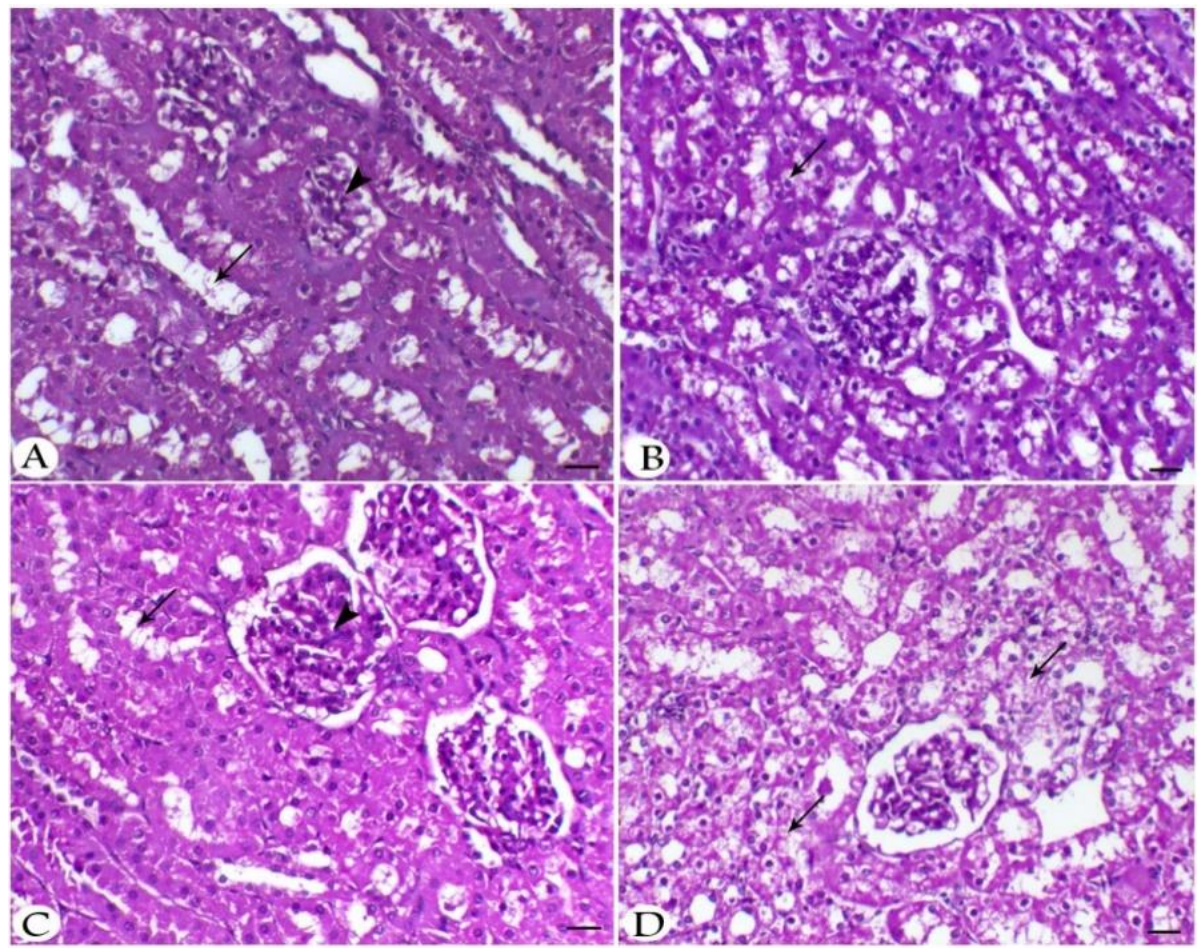

Figure 4:A) Kidney of room temperature (R) Rex rabbits showing normal renal glomeruli and tubules (arrowhead and arrow respectively), H\&E, bar $=40 \mu \mathrm{m}$. B) Kidney of heat stressed (HS) Rex rabbits showing marked degenerative changes within the lining epithelium of the tubules (arrows), H\&E, bar= 40 $\mu \mathrm{m}$. C) Kidney of R New Zealand rabbits showing normal renal glomeruli and tubules (arrowhead and arrow respectively), H\&E, bar $=40 \mu \mathrm{m}$. D) Kidney of HS New Zealand rabbits showing marked degenerative changes within the lining epithelium of the tubules (arrows), H\&E, bar $=40 \mu \mathrm{m}$ 

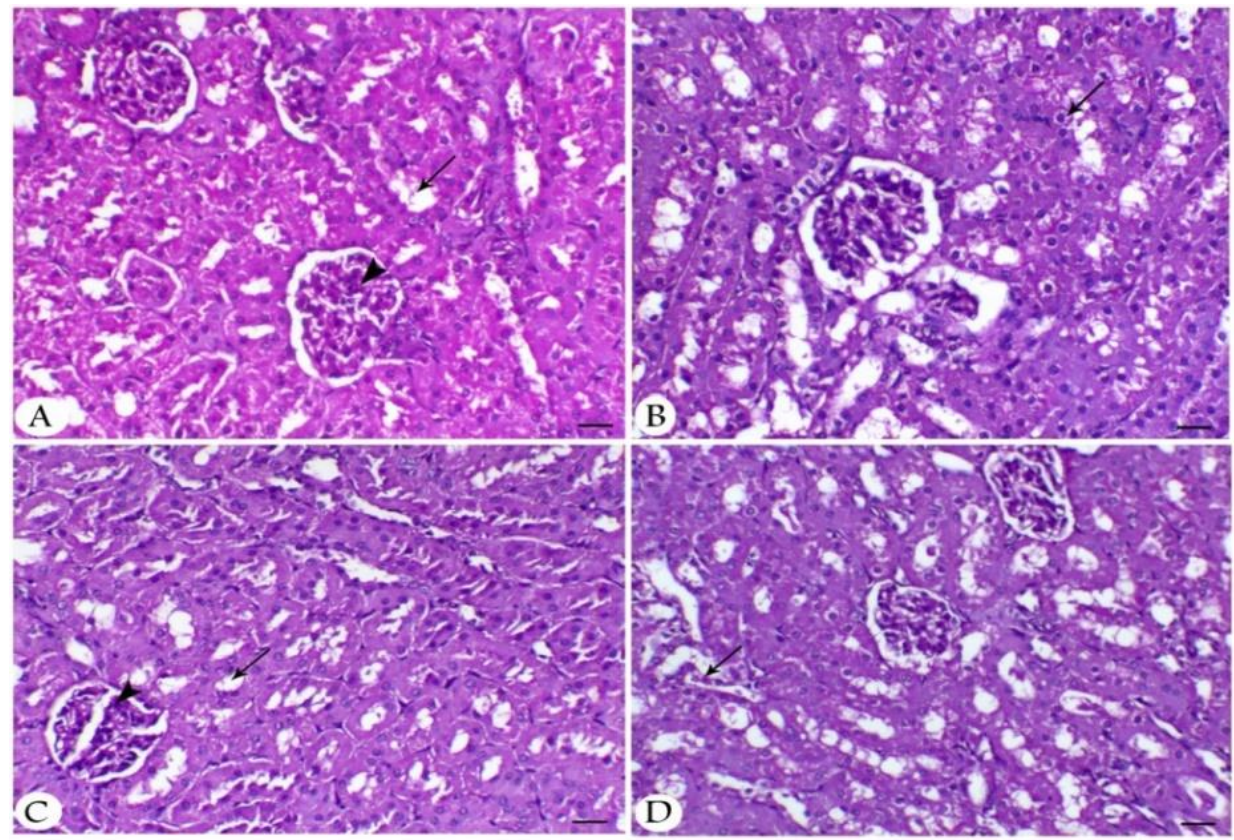

Figure 5:A) Kidney of room temperature (R) Rex rabbits with $1 \mathrm{mg} / \mathrm{L}$ nano-chromium (T1) showing normal renal glomeruli and tubules (arrowhead and arrow respectively), H\&E, bar $=40 \mu \mathrm{m}$. B) Kidney of HS Rex rabbits T1 showing mild degenerative changes within the lining epithelium of the renal tubules (arrow), H\&E, bar $=40 \mu \mathrm{m}$. C) Kidney of R New Zealand rabbits $\mathrm{T} 1$ showing normal renal glomeruli and tubules (arrowhead and arrow respectively), H\&E, bar $=40 \mu \mathrm{m}$. D) Kidney of HS New Zealand rabbits T1 showing mild degenerative changes within the lining epithelium of the renal tubules (arrow), $\mathrm{H} \& \mathrm{E}$, bar $=40 \mu \mathrm{m}$
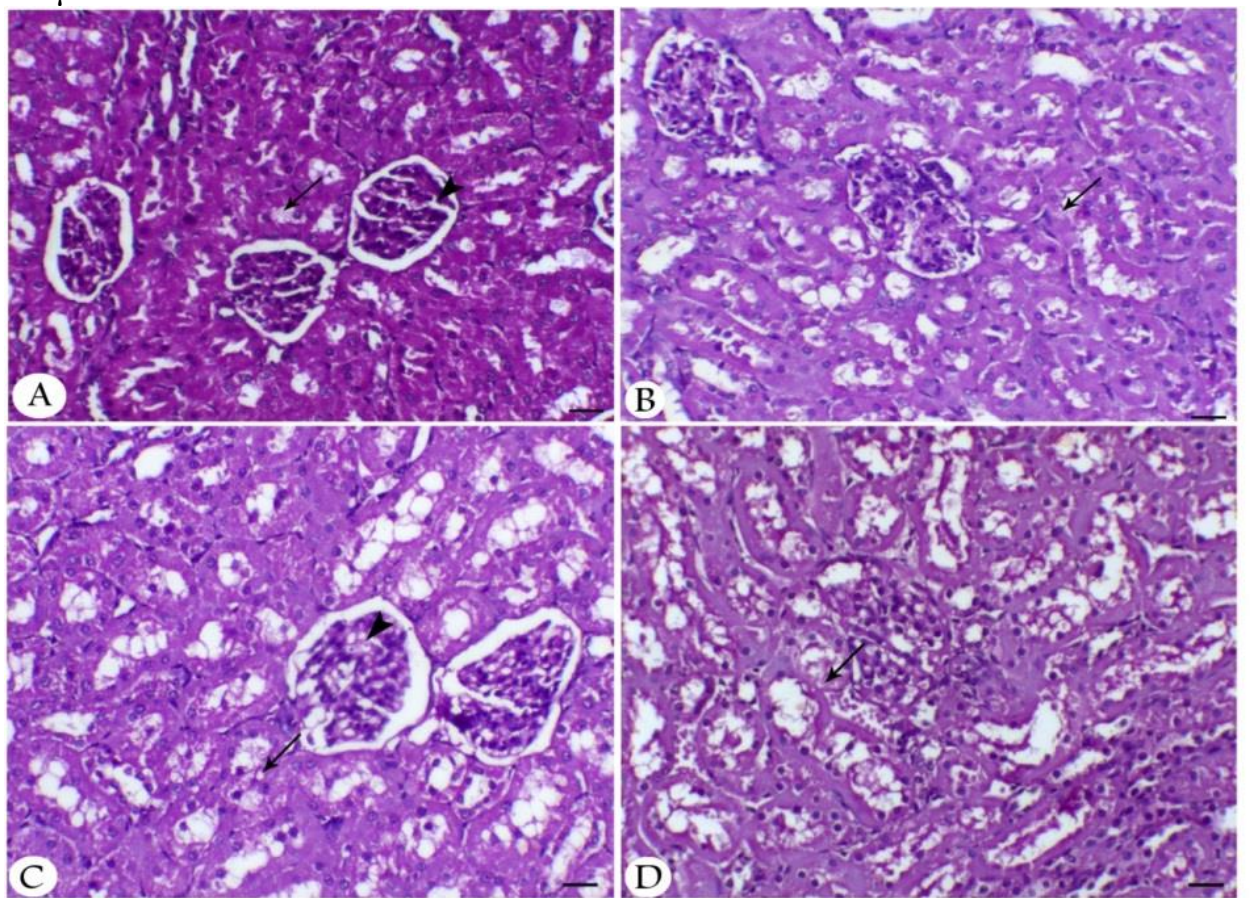

Figure 6:A) Kidney of room temperature (R) Rex rabbits with $2 \mathrm{mg} / \mathrm{L}$ nano-chromium (T2) showing normal renal glomeruli and tubules (arrowhead and arrow respectively), H\&E, bar $=40 \mu \mathrm{m}$. B) Kidney of heat stressed (HS) Rex rabbits T2 showing normal renal glomeruli and mild vacuolation of the renal tubular epithelium (arrow), H\&E, bar $=40 \mu \mathrm{m}$. C) Kidney of R-T2 New Zealand rabbits showing normal renal glomeruli (arrowhead) and mild vacuolation of the renal tubular epithelium (arrow), H\&E, bar $=40$ $\mu \mathrm{m}$. D) Kidney of HS-T2 New Zealand rabbits showing normal renal glomeruli (arrowhead) and mild vacuolation of the renal tubular epithelium (arrow), $\mathrm{H} \& \mathrm{E}$, bar $=40 \mu \mathrm{m}$ 

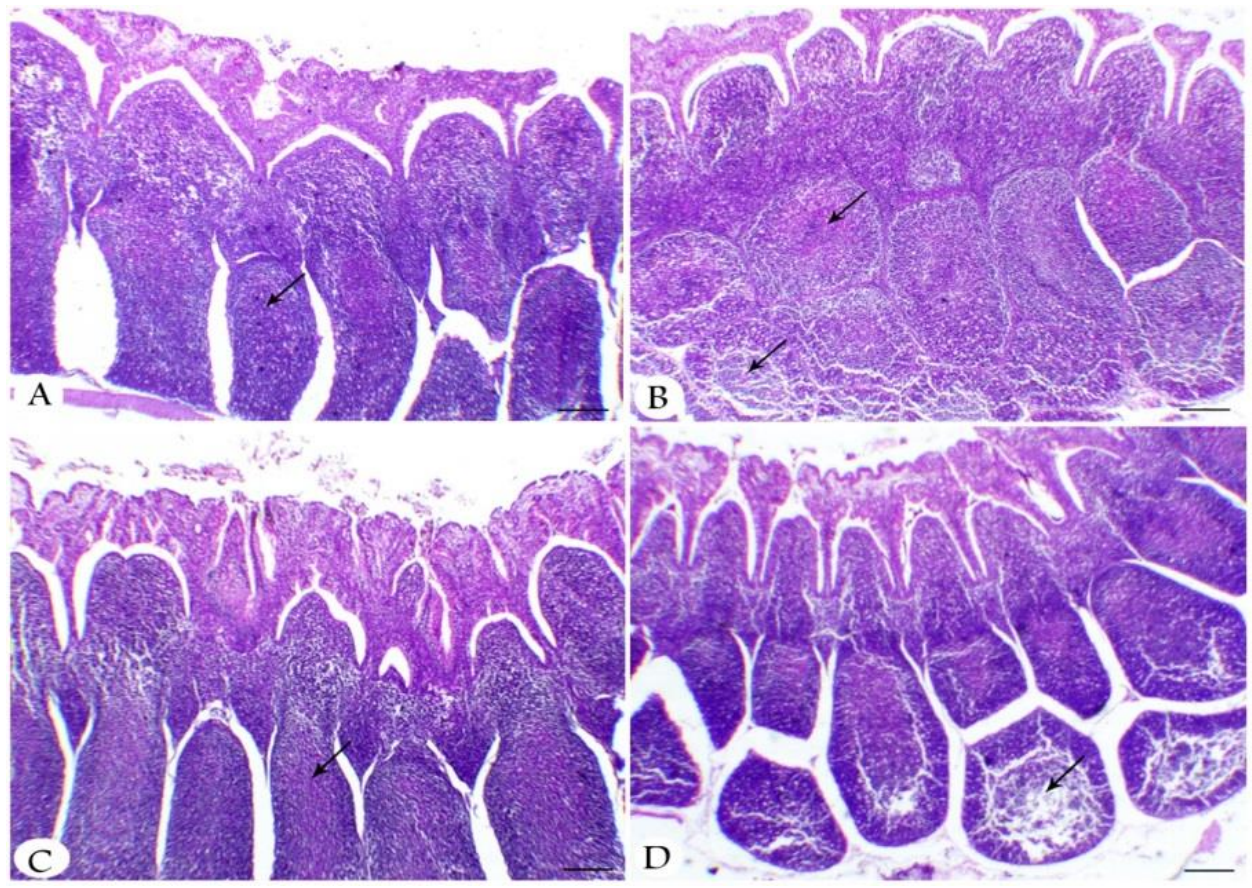

Figure 7: A) Appendix of room temperature (R) Rex rabbits showing normal lymphoid follicles covered with epithelial covering (arrow), H\&E, bar $=200 \mu \mathrm{m}$. B) Appendix of heat stressed (HS) Rex rabbits showing mild degree of lymphoid depletion of the germinal center of the follicles (arrow), H\&E, bar= $200 \mu \mathrm{m}$. C) Appendix of R New Zealand rabbits showing normal lymphoid follicles covered with epithelial covering (arrow), H\&E, bar $=200 \mu \mathrm{m}$. D) Appendix of HS New Zealand rabbits showing lymphoid depletion of the germinal center of the basal follicles (arrow), H\&E, bar $=200 \mu \mathrm{m}$

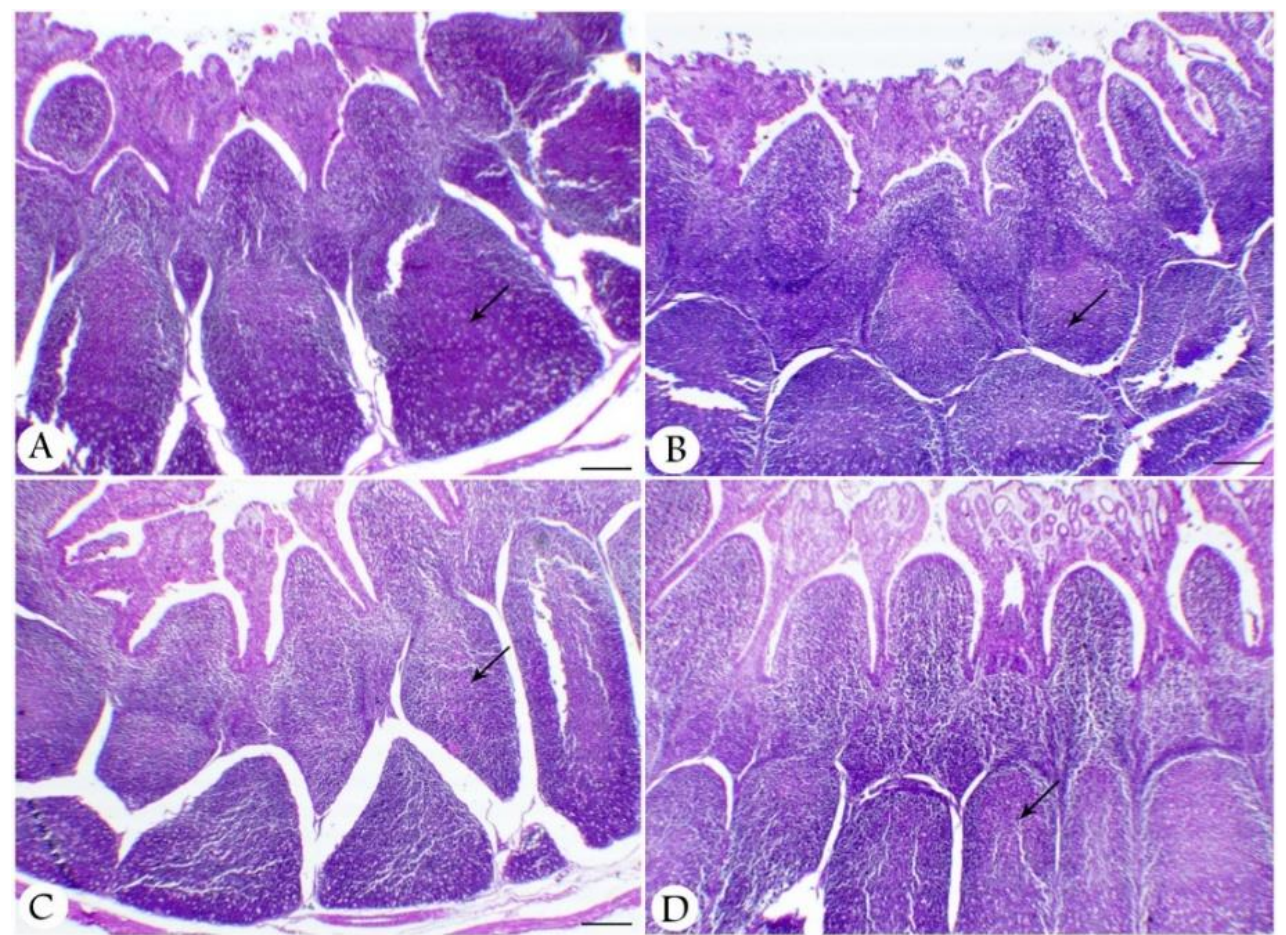

Figure 8: A) Appendix of room temperature (R) rabbits treated with $1 \mathrm{mg} / \mathrm{L}$ nano-chromium (T1) showing normal lymphoid follicles (arrow), H\&E, bar $=200 \mu \mathrm{m}$. B) Appendix of heat stressed (HS)-T1 Rex rabbits showing normal lymphoid follicles (arrow), H\&E, bar $=200 \mu \mathrm{m}$. C) Appendix of R-T1 New Zealand rabbits showing normal lymphoid follicles (arrow), H\&E, bar $=200 \mu \mathrm{m}$. D) Appendix of HS-T1 New Zealand rabbits showing normal lymphoid follicles (arrow), H\&E, bar $=200 \mu \mathrm{m}$. 


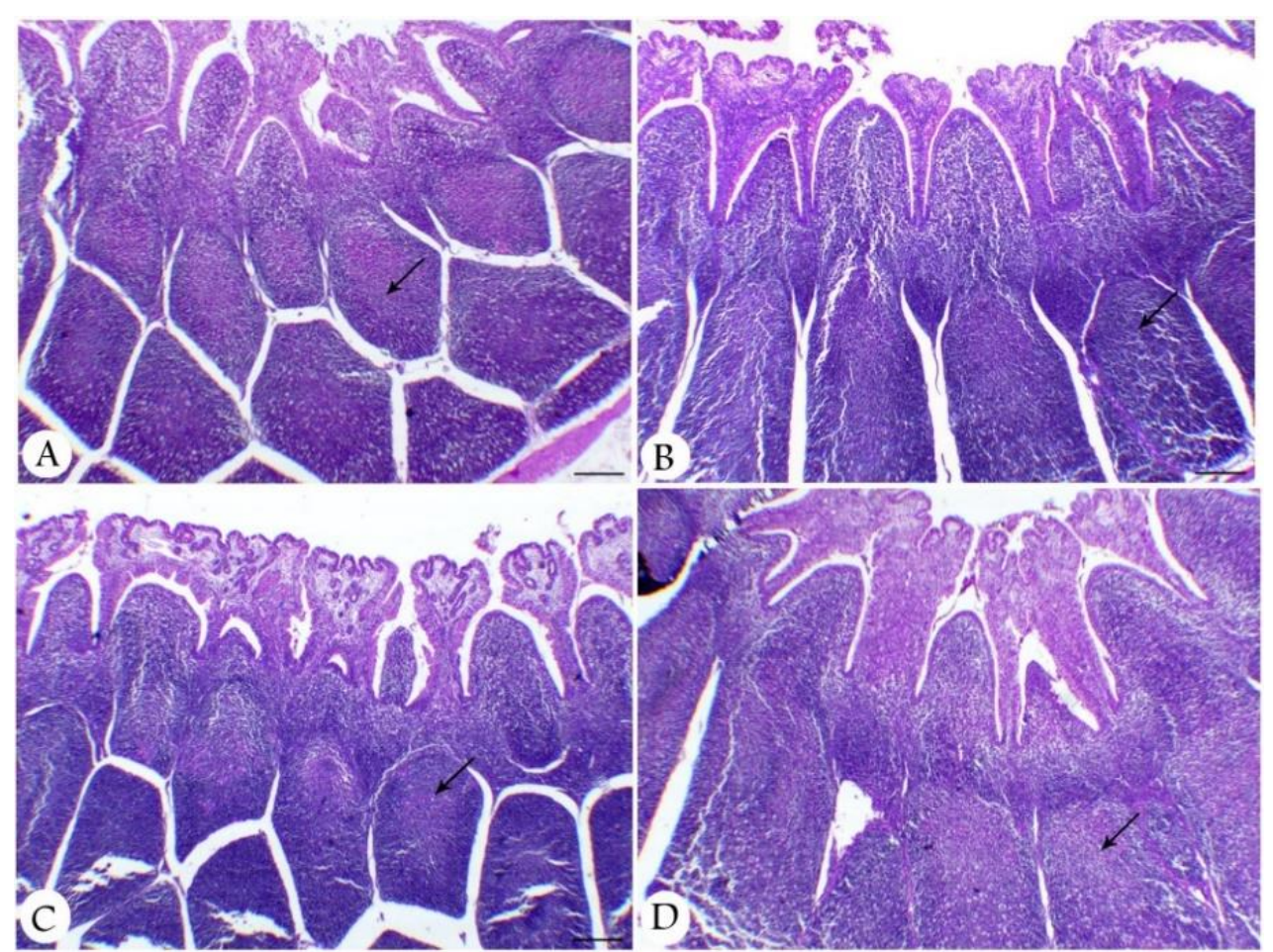

Figure 9: A) Appendix of room temperature (R) rabbits treated with $2 \mathrm{mg} / \mathrm{L}$ nano-chromium (T2) showing normal lymphoid follicles (arrow), H\&E, bar $=200 \mu \mathrm{m}$. B) Appendix of heat stressed (HS) rabbits T2 showing normal lymphoid follicles (arrow), H\&E, bar $=200 \mu \mathrm{m}$. C) Appendix of New Zealand R-T2 rabbits showing normal lymphoid follicles (arrow), H\&E, bar $=200 \mu \mathrm{m}$. D) Appendix of HS-T2 New Zealand rabbits showing normal lymphoid follicles (arrow), H\&E, bar $=200 \mu \mathrm{m}$

\section{Kidney}

When both breeds were exposed to room temperature conditions and untreated with nano-chromium they showed normal glomeruli and tubules (Figure 4-A and C). Kidneys of animals exposed to heat stress, but also untreated with nano-chromium particles showed degenerative changes within the lining of the epithelium of the renal tubules. This is likely due to the cytolytic response of the tissues by the heat followed by endotoximia that enhanced the release of inflammatory cytokines and consequently caused vascular endothelium injury (19). This appeared as degenerative changes in tubular lining epithelium in this study.

Figure 5-A and $\mathrm{C}$ showed normal renal and glomerular structures when $1 \mathrm{mg} / \mathrm{L}$ of nanochromium was administered. This is interrupted to mean that this concentration of nanochromium is safe and does not alter the renal structure in rabbits housed in room temperature conditions. This level of nano-chromium also decreased, but did not remove, the degenerative changes resulting from heat stress in both breeds. While the addition of $2 \mathrm{mg} / \mathrm{L}$ nano-chromium did ameliorate the degenerative changes in the heat stressed rabbits, this was replaced by mild vacuolation in lining epithelium. This may be due to glucose uptake by the cell increased by addition of this concentration (17) rather than toxicity.

\section{Appendix}

Animals of both breeds that were not treated with nano-chromium and kept under room temperature conditions appeared to have normal lymphoid follicles, as they were covered with epithelium. This indicates that this temperature was comfortable for the immune system of the rabbits. On the other hand, the groups that were exposed to heat stress and untreated with nano-chromium appeared to have a lymphoid depletion of the germinal center of the follicle (Figure 7-B and D). This may be due to the heat stress enhanced the production of ROS (20) that lead to death of 
most of cells (21), including immune cells and resulted in lymphoid depletion.

The addition of both 1 and $2 \mathrm{mg} / \mathrm{L}$ of nanochromium had the same effect on appendix tissues during heat stress. The addition of nano-chromium prevented the lymphoid depletion resulting from this stress (Figure 8-B and D; Figure 9-B and D). These results may be due to the catalytic effect of $\mathrm{Cr}$ III on the $\mathrm{H}_{2} \mathrm{O}_{2}$ inactivating enzyme, consequently decreasing the cell apoptosis (22). The structure of the appendix was not altered in groups treated with $2 \mathrm{mg} / \mathrm{L}$ of nano-chromium, but not exposed to heat stress. This in the agreement with Yucesoy et al. (23), that illustrated that $\mathrm{Cr}$ salts do not have an effect on the immune system cells.

\section{Conclusion}

In conclusion, addition of $2 \mathrm{mg} / \mathrm{L}$ nanochromuim particles to the drinking water of the heat stressed rabbits could be used to alleviate the granular degenerative changes and the sinusoidal congestion of the rabbit liver. As well as to ameliorate the effects of the previous concentration on the degenerative changes in the epithelium lining renal tubules. It is also able to reduce the lymphoid depletion in the lymphoid follicles of the rabbit appendix.

\section{References}

1. Fayez I, et al., Thermoregulation in rabbits. Cahiers Options Mediterraneennes (CIHEAM) 1994.

2. Hernandez-Lopez JR, et al., Thermal Effect of Acute and Chronic Stress on Hepatic and Renal Tissue of the Pacific Sardine, Sardinops sagax caeruleus (Jenyns, 1842)/Efecto del Estres Termico Agudo y Cronico Sobre el Tejido Hepatico y Renal de la Sardina del Pacifico, Sardinops sagax caeruleus (Jenyns, 1842). International Journal of Morphology 2018; 36(1): 212-21.

3. Barry MA, Behnke CA, and Eastman A, Activation of programmed cell death (apoptosis) by cisplatin, other anticancer drugs, toxins and hyperthermia. Biochemical pharmacology 1990; 40(10): 2353-62.

4. Zhang HJ, et al., Heat-induced liver injury in old rats is associated with exaggerated oxidative stress and altered transcription factor activation. The FASEB journal 2003; 17(15): 2293-5.

5. Ando M, et al., Age-related effects of heat stress on protective enzymes for peroxides and microsomal monooxygenase in rat liver. Environmental health perspectives 1997; 105(7): 726.

6. Aengwanich W, and Simaraks S, Pathology of heart, lung, liver and kidney in broilers under chronic heat stress. Pathology 2004; 26(3): 418.

7. Ondruska L, et al., Influence of elevated ambient temperature upon some physiological measurements of New Zealand White rabbits. Veterinarni Medicina 2011; 56(4): 180-6.

8. Raut $\mathrm{S}$, et al., Effect of trivalent chromium on haemato-biochemical and histopathological parameters at higher doses in broilers. Indian Journal of Veterinary Pathology 2012; 36(1): 73-9.

9. Berenjian A, et al., Effect of Chromium Nanoparticles on Physiological Stress Induced by Exogenous Dexamethasone in Japanese Quails. Biological trace element research 2017; 1-8.

10. Okada S, Suzuki M, and Ohba H, Enhancement of ribonucleic acid synthesis by chromium (III) in mouse liver. Journal of inorganic biochemistry 1983; 19(2): 95-103.

11. Pei Y, Wu Y, and Qin Y, Effects of chronic heat stress on the expressions of heat shock proteins $60,70,90, \mathrm{~A} 2$, and HSC70 in the rabbit testis. Cell Stress and Chaperones 2012; 17(1): 817.

12. Iqbal T, Tufail $\mathrm{S}$, and Ghazal $\mathrm{S}$, Synthesis of Silver, Chromium, Manganese, Tin and Iron Nano Particles by Different Techniques. International Journal of Nanoscience and Nanotechnology 2017; 13(1): 19-52.

13. Luna LG, Manual of histologic staining methods of the Armed Forces Institute of Pathology. 1968.

14. Kikusato M, and Toyomizu M, Heat stressinduced overproduction of mitochondrial reactive oxygen species is down-regulated in laying-type chickens, in Energy and protein metabolism and nutrition in sustainable animal production. 2013; Springer 267-8.

15. Orrenius $S$, Reactive oxygen species in mitochondria-mediated cell death. Drug metabolism reviews 2007; 39(2-3): 443-5.

16. Pitts J, What Causes a Congested Liver? Healthguidance for better health, 2018.

17. Huskisson E, Maggini S, and Ruf M, The role of vitamins and minerals in energy metabolism and well-being. Journal of international medical research 2007; 35(3): 277-89. 
18. Muthulingam $\mathrm{M}$, et al., Impact of heavy metal, chromium on glycogen contents in gill, liver and kidney of freshwater fish, Channa striatus $(\mathrm{BLOCH})$ International Journal of Current Research and Development 2017; 5(1): 1-9.

19. Bouchama A, and Knochel JP, Heat stroke. New England journal of medicine 2002; 346(25): 1978-88.

20. Yang L, et al., Effects of acute heat stress and subsequent stress removal on function of hepatic mitochondrial respiration, ROS production and lipid peroxidation in broiler chickens. Comparative Biochemistry and Physiology Part C: Toxicology \& Pharmacology 2010, 151(2): 204-8.
21. Circu ML, and Aw TY, Reactive oxygen species, cellular redox systems, and apoptosis. Free Radical Biology and Medicine 2010. 48(6); 74962.

22. Błasiak J, and Kowalik J, A comparison of the in vitro genotoxicity of tri-and hexavalent chromium. Mutation Research/Genetic Toxicology and Environmental Mutagenesis 2000; 469(1): 135-45.

23. Yücesoy $B$, et al, In vitro effects of various metals on natural killer cell activity in cultured human lymphocytes. Immunopharmacology and immunotoxicology 1999; 21(3): 599-7. 